\title{
Illegitimacy Is Dangerous: How Authorities Experience and React to Illegitimacy
}

\author{
Phillip Atiba Goff, Liana Maris Epstein, Avital Mentovich, Kavita S. Reddy \\ University of California, Los Angeles, USA \\ Email: goff@psych.ucla.edu
}

Received December $21^{\text {st }}, 2012$; revised January $23^{\text {rd }}, 2013$; accepted February $24^{\text {th }}, 2013$

\begin{abstract}
Research on legitimacy has focused on subordinate groups to the exclusion of authority figures. The present research explores how authorities experience concerns with their own legitimacy. We do so in the context of law enforcement asked to enact a legitimacy-challenging policy: cross-deputization (requiring police to enforce immigration laws similar to Arizona's SB1070). We expect that authorities' perceptions of their own legitimacy to rest on two factors: a) their own judgments of policies they enforce; and b) how they imagine subordinates would react to the enforcement of those policies. We examine the role of these factors on officers' sense of anxiety and physical safety. Results reveal that officers' feelings of safety are driven both by their own views and, to a greater extent, by how they imagine subordinates would react to the policy. These results demonstrate the importance of police legitimacy to officers' perceptions of their own safety, a vital factor in maintaining low levels of police/community conflict.
\end{abstract}

Keywords: Legitimacy; Law Enforcement; Public Policy; Power

\section{Introduction}

"I don't worry about...approaching people, you know. I know, if I treat them right, treat them with respect, they do the same. People respect us, what we do. We have a good reputation. So, no, I don't worry about safety. We are safe because we are fair."-Anonymous Police Officer

The above quote is how an officer responded to the question, "What makes you feel unsafe?" While one may expect officers' safety to depend on their ability to use coercive force, the above officer links his/her safety to the existence of mutually respectful relations between the police and their constituents. To him/ her, the greatest threat to safety is the potential loss of respect and legitimacy from whom he/she is sworn to protect. The cost of losing legitimacy for an officer, then, is the potential to lose one's life.

This response is understandable if we consider the foundational role of legitimacy in social institutions. Legitimacy provides authorities with the justification to hold power, to prescribe behaviors, and to enforce laws (Kelman \& Hamilton, 1989; Tyler, 2006a; Tyler, 2006b). A lack of legitimacy, therefore, decreases citizens' willingness to follow laws, making the ordinary task of enforcement more difficult and, potentially, more dangerous. While the threat of declining legitimacy is strongly pronounced among law enforcement officials - the concerns expressed by the above police officer serves as one example-it has not received empirical attention. In fact, subordinate experiences with legitimacy have been studied extensively (Jackson et al., 2012a; Lind \& Tyler, 1988; Tyler, 2006b, 2008; Tyler \& Huo, 2002; Tyler \& Wakslak, 2004). However, the experiences of dominant and/or powerful groups with their own legitimacy have rarely been examined.

The present paper aims to address this gap in legitimacy research by linking a declining sense of legitimacy to a declining sense of safety among individuals in a position of authority. Moreover, we do so within the context of an important and under-explored problem in the world-immigration policy in the United States. The goal of the present research, therefore, is simultaneously to expand the theoretical understanding of procedural justice theory and apply it to the context of law enforcement in the arena of a controversial - and consequentialproblem. Taken together, this research is intended to serve as an important first step towards understanding how the powerful value their own legitimacy and towards understanding how that should shape the coming debates on immigration in the United States.

Exploring how the powerful (and not just the powerless) experience their own legitimacy, we offer several extensions to the current research on legitimacy. First we explore the roots of legitimacy judgments among individuals in a position of authority. Drawing upon research on legitimacy and social power we propose that authorities' experiences of their own legitimacy are anchored in two factors: a) their personal judgments of their legitimacy; and b) their perceptions of how legitimate they appear in the eyes of relevant subordinates. Second, we examine the relative importance of these two factors in driving the adverse affective consequences of declining legitimacythe fear of being socially or physically endangered. In the absence of research on how authorities experience legitimacy, we consider three possible options: that authority figures are influenced by their own perceptions of their legitimacy, but not by that of others; that they are affected by others' perceptions of their legitimacy, but not by their own; or that they are influenced by both others' and their own perceptions of their legitimacy.

First, it is possible that authorities are affected by their personal views about legitimacy and are unaffected by how subordinates view them. In this case, authorities who believe they act fairly and legitimately will not fear that their interactions with 
community members will be anxiety provoking or dangerous, even if community members think otherwise. A second option is that, more than their personal views, authority figures are affected by how they think subordinates view them. In that case, authorities will fear uncomfortable and/or dangerous interactions with the community if they believe that they appear illegitimate to subordinates, regardless of their personal views about their behavior. A third option is that authorities are affected both by their own perception of legitimacy as well as by how subordinates view them.

These possibilities are tested in a timely context of police officers' responses to the enforcement of the controversial policy of cross-deputization - made nationally salient by Arizona's SB 1070 law, recently (partially) enjoined by the United States Supreme Court. This policy mandates that municipal police and sheriffs enforce federal immigration laws, in some cases requiring officers to stop individuals suspected to be in the country illegally and request proof of legal residence. In line with our conceptualization, we examine the independent effect of officers' personal endorsement of cross-deputization policies and their concern with losing respect from Latinos - the group that public discourse suggests will be disproportionally targeted by these policies (Epstein \& Goff, 2011; Goff, Epstein, \& Reddy, in press).

\section{How Do the Powerful Experience Legitimacy?}

Legitimacy confers the right to command and promotes the duty to obey. People defer to legitimate authorities not out of fear of punishment, but simply because they feel it is right to do so. Legitimacy is therefore crucial for maintaining social institutions (Tyler, 2006a, 2006b, 2008). The importance of legitimacy arises mainly in social organizations built on hierarchy and containing power differentials. Within hierarchical settings legitimacy reflects the agreement of subordinates to accept authorities' power over them (French \& Raven, 1959; Jost \& Major, 2001). In classic work concerning the bases of social power (French \& Raven, 1959), legitimacy is considered an important source of power, allowing authorities to influence subordinates through consent rather than coercion-something crucial to avoiding the use of coercive force (Alpert \& Dunham, 1992).

Recent research in organizational psychology echoes these early insights on the importance of legitimacy while also highlighting the detrimental consequences of perceived illegitimacy. Without legitimacy, subordinates are not likely to accept authorities' directive and may publicly follow them only out of fear of punishment (French \& Raven, 1959; Tyler 2003; Tyler \& Huo 2002; Tyler \& Wakslak, 2004; Jackson et al., 2012b).

While it is clear how subordinates respond to perceived illegitimacy, research has largely ignored how challenges to legitimacy may impact high-power authorities. Legitimacy has primarily been explored as a property bestowed by subordinates to authorities and not as something directly experienced by authorities themselves. Even the few existing works examining legitimacy judgments among police authorities have looked at officers' perception of their supervisors as the precursor for perceived organizational legitimacy (Tyler, Callahan, \& Frost, 2007). In other words, research considering what shapes legitimacy among law enforcement has done so within an organizational context that casts traditional authorities (i.e., police) as subordinates themselves.

\section{The Consequences of Authorities' Experiences of Illegitimacy}

How do experiences of illegitimacy influence the ways authorities use their power and interact with subordinates? Research on legitimacy and power suggests that the loss of legitimacy functions as a power threat, eliciting behavioral inhibition and anxiety. In the power literature, declining legitimacy is linked to declining power. According to French and Raven's (1959) typology of power, there is a direct connection between the degree of authorities' legitimacy and their power since legitimate authorities are better able to prescribe behaviors and influence subordinates. While French and Raven, demonstrate how loss of legitimacy from subordinates weakens authorities power, their reasoning would suggest that authorities who see themselves as illegitimate and unable to impact subordinates would also experience weakening power.

Consistent with this idea, recent studies on social power show that tendencies normally associated with having power (approach orientation) or lacking it (inhibition orientation) are no longer pronounced in the absence of legitimacy (Carver \& White 1994; Lammers, Galinsky, Gordjin, \& Otten, 2008). In line with these findings, we suggest that declining legitimacy compromises authorities' power, leading them to be more behaviorally inhibited, attuned to threat, and experience diminished safety-particularly in the presence of those among whom their legitimacy is threatened.

\section{The Present Research}

The present research examines experiences of illegitimacy among authorities using the responses of police officers to cross-deputization. The growing controversy surrounding crossdeputization policies (Amendola et al., 2008; Burbank, Goff, \& Keesee, 2010; Epstein \& Goff, 2011; Goff et al., 2012; Major Cities Chiefs Immigration Committee, 2006) offers a fruitful arena for studying how authority figures negotiate legitimacychallenging policies.

Consistent with our theorizing we assessed officers' legitimacy perception along two dimensions. First, we looked at officers' personal views about the legitimacy of cross-deputization policies by asking how fair these policies are. Second, we assessed officers' perception of how the enforcement of cross-deputization would affect the respect they receive from Latinos - the group most associated with cross-deputization legitimacy (Epstein \& Goff, 2011; Goff et al., 2012). We focused on respect as an axis of legitimacy in this context since other aspects of legitimacy (such as compliance or cooperation) are less applicable. Cross-deputization policies require compliance from all citizens (any individual that is stopped by the police for the purpose of identification has to provide documentation) and voluntary cooperation from none (no individuals - not even undocumented immigrants - are expected to voluntarily show up in police station for the purpose of identification). With compliance and cooperation measures being less relevant in this context, we decided to gauge the concern of potential loss of respect from Latinos as a proxy for the concern of losing legitimacy.

Perceptions of illegitimacy are hypothesized to predict greater anxiety among police officers, particularly in encounters with subordinates among which their legitimacy is threatened. Because Latinos are the group most strongly associated with 
undocumented immigration (Epstein \& Goff, 2011; Goff et al., 2012), officers are expected to experience increased anxiety and diminished safety particularly when interacting with Latino suspects.

In the absence of previous research, we cannot make specific predictions about which of the two proposed aspects of legitimacy - self-perceptions or perceptions of others-would be more predictive of officers' increased anxiety and diminished safety. Consequently, we tested each of the three possible relationships (self-perceptions, others' perceptions, or both) using structural equation modeling in which each of the proposed components of legitimacy was modeled as a latent factor. We then examined the unique contribution of each factor to officers' sense of anxiety and perceptions of safety.

\section{Methods}

We recruited police officers from two police departments:

\section{Salt Lake City Police Department Participants}

Eighty-four officers from the Salt Lake City Police Department (SLCPD) participated in the survey. The SLCPD sample was $89 \%$ male, with a mean age of $38.91(S D=8.38)$. The racial composition of the sample was $84 \%$ White, $0 \%$ Asian, $2 \%$ Black, $7 \%$ Latino, and $7 \%$ other. A single item measuring political ideology on a scale from 1 (very liberal) to 7 (very conservative) illustrated that, on average, the sample was slightly politically conservative $(M=4.66 ; S D=1.35)$. SLCPD officers were recruited during roll call and invited to participate in the survey.

\section{San Jose Police Department Participants}

Thirty-one officers from the San Jose Police Department (SJPD) participated in the survey. The SJPD sample was 93\% male, with a mean age of $39.90(S D=7.03)$. The racial composition of the sample was 52\% White, $8 \%$ Asian, 2\% Black, 28\% Latino, and $10 \%$ other. Responses to the same measure of political ideology described above illustrated that, on average, the sample was slightly politically conservative $(M=5.02 ; S D=$ 1.18). SJPD officers were recruited through announcements in roll call but filled out the survey during the course of their shift.

We found no statistically significant differences between the two departments; therefore we collapsed across departments and report the combined results.

\section{Procedure}

The survey took approximately 20 minutes to complete. All subjects were informed that no identifying information would be collected and that supervisors would not be given information with regards to their data, including whether or not they participated.

\section{Measures}

Cross-Deputization Endorsement: Officers' perceptions of the legitimacy of cross-deputization were assessed using fouritem scale (each item was rated on a 5-point Likert scale). Items included, "police officers should be responsible for verifying a person's immigration status". This scale was highly reliable $(\alpha$ $=.91)$. Higher scores in this scale indicate greater perceived legitimacy of cross-deputization policies.
Respect: To examine officers' perception of how they appear in the eyes of relevant constituents, we assessed officers' beliefs about the respect they would receive from Latino community members while enforcing cross-deputization policies. Perceived respect was measured with a three-item scale (each item was rated on a 5-point Likert scale) that asked if officers felt respected, approved of, and valued. These three items were taken from work by Molina and Huo on subgroup respect (2006). Officers were asked to imagine how they would feel if they were asked to enforce cross-deputization policy. They were then administered the items, which included, "Latinos value the opinions and ideas of police officers." This scale was highly reliable for responses to perceptions of Latino residence $(\alpha=.95)$. For ease of interpretation, scores were reverse coded such that higher scores indicate greater predicted loss of respect from Latinos.

Anxiety: Anxiety was measured with a six-item scale, where each item was rated on a 5-point Likert scale. Items were taken from work by Van Zomeren, Fischer, \& Spears (2007), who used six emotional prompts (uneasy, nervous, threatened, uncertain, uncomfortable, anxious) to assess the intergroup anxiety evoked by seeing homeless people. The frame for these items was adapted to query participants about how they felt when approaching a Latino suspect on the street. This scale was administered asking officers to answer assuming they would enforce cross-deputization policy. The scale was highly reliable $(\alpha=.90)$.

Safety-Gap: Officers' sense of physical safety was measured with two items on a 5-point Likert scale. One item referenced White suspects and the other Latino suspects. Items included, "In my city, I feel safe approaching a [White/Latino] suspect on the street." Safety gap scores were created by subtracting officers' perceived safety interacting with a Latino suspect from their perceived safety interacting with a White suspect. Higher scores in this scale indicate a wider race-based safety gap in favor of the white group.

\section{Results}

We modeled the two independent legitimacy concerns - officers' perception of the legitimacy of cross-deputization and the respect they expect to receive from Latinos - as predictors of two outcomes variable: officers' reported anxiety in encounters with Latinos; and their sense of safety in interaction with Latino (versus White) suspects. We used Mplus 5.2 to test this model. The two independent predictors of legitimacy were modeled as latent variables. We examined the paths coefficients between these two latent variables and officers' increased anxiety and sense of safety in future encounters with Latinos. The results of this analysis are presented in Figure 1.

As Figure 1 shows, the two legitimacy constructs formed two distinct latent variables that were not significantly correlated $(r=.13, p>.2)$. That suggests that, as hypothesized, personal perception of legitimacy (anchored in officers' assessments of cross-deputization fairness) was distinct from the perceptions of legitimacy from community members. In other words, the results suggest that officers that support cross-deputization policy can still independently be concerned about losing respect from Latinos as a result of cross-deputization enforcement (and vice versa).

Next, we examined which of the two features of authorities' perception of legitimacy better predicted officers' concern with 


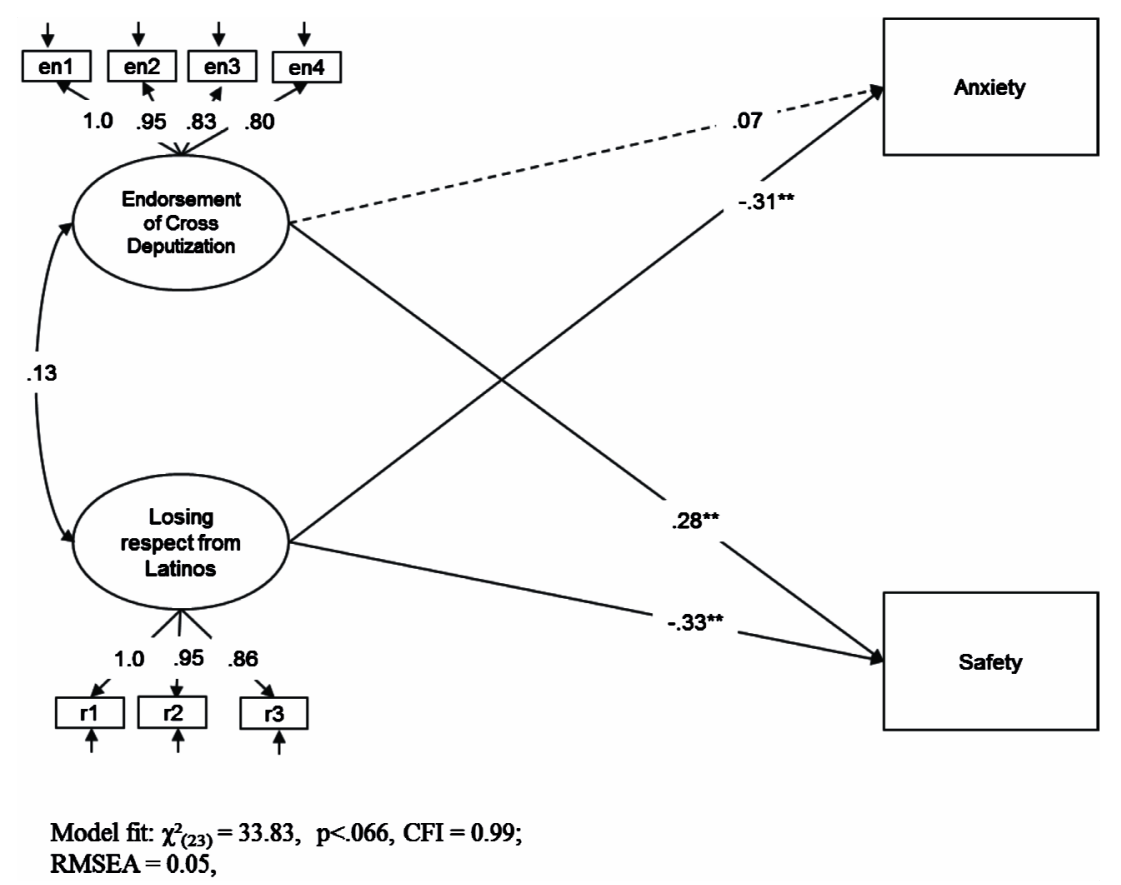

Figure 1.

The relations between officers' perception of legitimacy and their sense of anxiety and safety.

their physical safety. The model showed an excellent fit for the data: $\chi^{2}(23, \mathrm{~N}=115)=33.83, p<.06, C F I=.99, S R M R=.041$, $R M S E A=.05$. As shown in Figure 1, both officers' endorsement of cross-deputization $(\beta=-.28, p<.001)$ and the fear of losing respect from Latinos $(\beta=.33, p<.001)$ were significantly associated with perceived safety gap in future policing encounters. Officers' endorsement of cross-deputization policies predicted diminished concern with their physical safety in future encounters with Latino suspects. Conversely, officers' perception that they would lose respect from Latinos following cross-deputization enforcement predicted heightened concern with their physical safety in future encounters with Latinos.

Our second dependent variable yielded similar, though not identical, patterns. Officers' reported anxiety in future encounters with Latinos was positively associated with the fear of losing respect from Latinos $(\beta=31, p<.001)$, but not with officers' endorsement of cross-deputization policies. That is, it was only the concern with losing respect from Latinos that predicted officers' anxiety in future encounters with Latinos.

Taken together, these results suggest that, while personal attitudes about the legitimacy of cross-deputization policies can impact officers' sense of safety, officers are more consistently affected by how they appear to subordinates. Conversely, the adverse affective consequences of lack of legitimacy are particularly pronounced in interactions with subordinates who are perceived to view authorities as illegitimate.

\section{Discussion}

The present research expands the literature on legitimacy by providing evidence of the ways it impacts the powerful rather than the powerless. We examined police authorities' experiences of legitimacy using both their own perception of the policy they enforce and their perceptions of how their community perceives them. Both factors predicted officers' concerns with their physical safety, while the fear of losing respect from Latinos singularly predicted officers' anxiety in future encounters with Latinos. These results support the supposition that loss of legitimacy leads to adverse consequences not only for subordinates, but also for authorities. When police officers enforce a policy that threatens their legitimacy, they experience greater anxiety and a diminished sense of safety in encounters with Latinos - the same community within which their legitimacy is most at risk.

Grounded in a theoretical expansion of legitimacy research, the results illuminate the conditions under which authorities can experience their own lack of legitimacy. For the powerful, personal views as well how they appear in the eyes of the powerless shape legitimacy experience. The finding that authorities are particularly concerned with how legitimate they appear to subordinates is consistent with the functional importance of legitimacy in power maintenance. Power holders depend on legitimacy to effectively use and sustain their power, therefore the failure to secure subordinates' acceptance is experienced by them as threatening.

This research also illuminates the important psychological consequences of illegitimacy experienced by authorities. We show that declining legitimacy leads authorities to experience anxiety and lack of safety. These results provide support to the argument that, without legitimacy, authorities experience consequences associated with lack of power. The idea that legitimacy and power are related in experiences of authority complements French and Raven (1959) classic studies on power. They showed that without legitimacy subordinates grant less power to authorities (in the sense that they are not willing to be influenced by them). Our results show that, without legitimacy, authorities act in ways equivalent to having less or no power, hesitating to use their mandate.

Our results further propose that the enforcement of legiti- 
macy-challenging laws may create a vicious cycle between police officers and the communities among which their legitimacy is challenged. If officers feel greater anxiety and less safety in interacting with Latinos, they may use harsher means of enforcement to secure their perceived safety; as a result, officers may be seen as even less legitimate among Latinos and would consequently feel even less safe. This idea is supported by research showing that officers who feel like they have lost control of a situation are more likely to use dominant force (Alpert et al., 2004). Though further research is needed to test these predictions, our research raises the possibility that racially charged law-enforcement policies actually endangers the safety of both officers and civilians. Still, if law enforcement and communities are safer when police are seen as legitimate, then this research is both necessary and urgent.

\section{REFERENCES}

Alpert, G. P., \& Dunham, R. G. (1992). Policing urban America. Long Grove, IL: Waveland Press. doi:10.1017/CBO9780511499449

Alpert, G. P., \& Dunham, R. G. (2004). Understanding police use of force: Officers, suspects, and reciprocity. Cambridge: Cambridge University Press.

Amendola, K. L., Williams, K. N., Hamilton, E. E., \& Puryear, V. (2008). Law enforcement executive views: Results from the conference survey. In M. Malina (Ed.), The role of local police: Striking a balance between immigration enforcement and civil liberties. Washington DC: Police Foundation.

Burbank, C., Goff, P. A., \& Keesee, T. L. (2010). Policing immigration: A job we do not want. Huffington Post. URL (last checked 3 May 2011).

http://www.huffingtonpost.com/chief-chris-burbank/policing-immigr ation-a-jo_b_602439.html

Carver, C. S., \& White, T. L. (1994). Behavioral inhibition, behavioral activation, and affective responses to impending reward and punishment: The BIS/BAS scales. Journal of Personality and Social Psychology, 67, 319-333. doi:10.1037/0022-3514.67.2.319

Epstein, L. M., \& Goff, P. A. (2011). Safety of liberty? The bogus tradeoff of cross-deputization policy. Analyses of Social Issues and Public Policy, 10, 1-11.

French Jr., J. R. P., \& Raven, B. H. (1959). The bases of social power. In D. Cartwright (Ed.), Studies in social power (pp. 150-167). Ann Arbor, MI: Institute for Social Research.

Goff, P. A., Epstein, L. M., \& Reddy, K. S. (in press). Crossing the line of legitimacy: The effect of cross-deputization on crime-reporting. Psychology, Public Policy, and Law.

Jackson, J., Bradford, B., Stanko, E. A., \& Hohl, K. (2012a). Just au- thority? Trust in the police in England and Wales. Oxon: Routledge. Jackson, J., Bradford, B., Hough, M., Myhill, A., Quinton, P., \& Tyler, T. R. (2012b). Why do people comply with the law? Legitimacy and the influence of legal institutions. British Journal of Criminology, 52, 1051-1071. doi:10.1093/bjc/azs032

Jost, J. T., \& Major, B. (2001). The psychology of legitimacy: Emerging perspectives on ideology, justice, and intergroup relations. New York: Cambridge University Press.

Kelman, H. C., \& Hamilton, V. L. (1989).Crimes of obedience: Toward a social psychology of authority and responsibility. New Haven, CT: Yale University Press

Lammers, J., Galinsky, A. D, Gordijn, E. H, \& Otten, S. (2008). Illegitimacy moderates the effects of power on approach. Psychological Science, 19, 558-564. doi:10.1111/j.1467-9280.2008.02123.x

Lind, E. A., \& Tyler, T. R. (1988). The social psychology of procedural justice. New York: Plenum.

Major Cities Chiefs Immigration Committee (2006). M.C.C. Immigration Committee recommendations for enforcement of immigration laws by local police agencies. URL (last checked 10 May 2011). http://www.majorcitieschiefs.org/pdf/position_statement_revised.pdf

Molina, L., \& Huo, Y. (2006). Is pluralism a viable model of diversity? The benefits and limits of subgroup respect. Group Processes \& Intergroup Relations, 9, 359-376. doi:10.1177/1368430206064639

Tyler, T. R. (2003). Procedural justice, legitimacy, and the effective rule of law. In M. Tonry (Ed.), Crime and justice, 30, 431-505.

Tyler, T. R. (2006a). Psychological perspectives on legitimacy and legitimation. Annual Review of Psychology, 57, 375-400. doi:10.1146/annurev.psych.57.102904.190038

Tyler, T. R. (2006b). Why people obey the law: Procedural justice, legitimacy, and Compliance (2nd ed.). Princeton, NJ: Princeton University Press.

Tyler, T. R. (2008). Procedural justice and the courts. Court Review, 44, 26-31.

Tyler, T. R., Callahan, P., \& Frost, J. (2007). Armed, and dangerous(?): Can self-regulatory approaches shape rule adherence among agents of social control. Law and Society Review, 41, 457-492. doi:10.1111/j.1540-5893.2007.00304.x

Tyler, T. R., \& Huo, Y. J. (2002). Trust in the law: Encouraging public cooperation with the police and courts. New York: Russell Sage Foundation.

Tyler, T. R., \& Wakslak, C. J. (2004). Profiling and police legitimacy: Procedural justice, attributions of motive, and acceptance of police authority. Criminology, 42, 253-281. doi:10.1111/j.1745-9125.2004.tb00520.x

Van Zomeren, M., Fischer, A., \& Spears, R. (2007). Testing the limits of tolerance: How intergroup anxiety amplifies negative and offensive responses to out-group-initiated contact. Personality and Social Psychology Bulletin, 33, 1686-1699. doi: $10.1177 / 0146167207307485$ 